analyses, writing the manuscript and sharing scientific discussions. L-M. Galerneau contributed to the study design, data collection and analyses, writing the manuscript and sharing scientific discussions. A-L. Borel contributed to the study design, analyses and revising the manuscript. O. Chabre contributed to the study hypothesis, study design, data collection and analyses, revising the manuscript and sharing scientific discussions. M. Sapene, B. Stach and J. Girey-Rannaud contributed to the study hypothesis, study design and data collection. R. Tamisier and P. Caron contributed to the study hypothesis, study design, data collection and analyses, writing the manuscript and sharing scientific discussions. N. Arnol performed the statistical analyses and contributed to revising the manuscript.

Prior abstract publication/presentation: French National Sleep Congress, Nantes, November 2015; American Thoracic Society Conference, San Francisco, May 2016.

\title{
References
}

Melmed S. Medical progress: acromegaly. N Engl J Med 2006; 355: 2558-2573.

Lugo G, Pena L, Cordido F. Clinical manifestations and diagnosis of acromegaly. Int J Endocrinol 2012; 2012: 540398.

3 Rosario PW. Frequency of acromegaly in adults with diabetes or glucose intolerance and estimated prevalence in the general population. Pituitary 2011; 14: 217-221.

4 Fatti LM, Scacchi M, Pincelli AI, et al. Prevalence and pathogenesis of sleep apnea and lung disease in acromegaly. Pituitary 2001; 4: 259-262.

5 Attal P, Chanson P. Endocrine aspects of obstructive sleep apnea. J Clin Endocrinol Metab 2010; 95: 483-495.

6 Abu Dabrh AM, Mohammed K, Asi N, et al. Surgical interventions and medical treatments in treatment-naïve patients with acromegaly: systematic review and meta-analysis. J Clin Endocrinol Metab 2014; 99: 4003-4014.

7 Katznelson L, Laws ER Jr, Melmed S, et al. Acromegaly: an endocrine society clinical practice guideline. J Clin Endocrinol Metab 2014; 99: 3933-3951.

8 Ip MS, Tan KC, Peh WC, et al. Effect of Sandostatin LAR on sleep apnoea in acromegaly: correlation with computerized tomographic cephalometry and hormonal activity. Clin Endocrinol (Oxf) 2001; 55: 477-483.

9 Colao A, Ferone D, Marzullo P, et al. Systemic complications of acromegaly: epidemiology, pathogenesis, and management. Endocr Rev 2004; 25: 102-152.

10 Reid TJ, Post KD, Bruce JN, et al. Features at diagnosis of 324 patients with acromegaly did not change from 1981 to 2006: acromegaly remains under-recognized and under-diagnosed. Clin Endocrinol (Oxf) 2010; 72: 203-208.

11 Rosario PW, Calsolari MR. Screening for acromegaly by application of a simple questionnaire evaluating the enlargement of extremities in adult patients seen at primary health care units. Pituitary 2012; 15: 179-183.

12 Rosario PW, Calsolari MR. Screening for acromegaly in adult patients not reporting enlargement of the extremities, but with arterial hypertension associated with another comorbidity of the disease. Arq Bras Endocrinol Metabol 2014; 58: 807-811.

13 Zoicas F, Kleindienst A, Mayr B, et al. Screening for acromegaly in patients with carpal tunnel syndrome: a prospective study (ACROCARP). Horm Metab Res 2016; 48: 452-456.

14 Kimmell KT, Weil RJ, Marko NF. Multi-modal management of acromegaly: a value perspective. Pituitary 2015; 18: 658-665.

\section{Introduction of the 13-valent pneumococcal conjugate vaccine in an isolated pneumococcal vaccine-naïve indigenous population}

To the Editor:

The introduction of pneumococcal conjugate vaccines (PCVs) has the greatest impact in populations that are most affected by pneumococcal carriage and disease, such as indigenous children [1]. Although $~ 10 \%$ of the South American population consists of indigenous people living in remote settings, to our knowledge PCVs have not been evaluated in native South American children. The Warao people are an Amerindian population residing in wooden houses along the Orinoco River delta in Venezuela. Almost one-third of Warao children die during childhood and respiratory tract infections are a major cause of death [2]. This study is the first to evaluate the impact of 13-valent (PCV13) vaccination on nasopharyngeal colonisation rates and antibody response in PCV-naïve indigenous South American children.

From May to November 2012, 504 Warao children aged 6 weeks to 59 months residing in nine communities were vaccinated. Before and at a median 6.7 weeks after primary PCV13 series we obtained nasopharyngeal swabs $(n=424)$ and serum samples $(n=421)$. The primary series consisted of three vaccine doses for children 
aged $\leqslant 6$ months and two and one dose(s) for children aged 7-23 months and 24-59 months, respectively, following Centers for Disease Control and Prevention guidelines [3]. Siblings of vaccinated children (aged 5-10 years, $n=190)$ and caregivers $(n=269)$ were included as unvaccinated community controls, bringing the total number of subjects sampled pre- and post-vaccination to $n=883$.

Pneumococcal serotype-specific immunoglobulin $G$ antibodies were measured using a fluorescent bead-based multiplex immunoassay. Antibody concentrations were log-transformed and compared using unpaired t-tests or ANOVA and Bonferroni post hoc tests. Nasopharyngeal samples were cultured using standard methods and serotyped using multiplex PCR. Since serotypes of serogroups 6, 9 and 19 could not be determined using PCR, the Quellung reaction was used. Carriage rates pre- and post-vaccination were compared using the McNemar test. We used single imputation using SPSS (IBM, Armonk, NY, USA) to correct for 43 samples in which the Quellung reaction failed to determine the serotype, which suffices in cases where the number of missing values is limited, as in our study [4].

The study was approved by the ethical committee of the Instituto de Biomedicina (Caracas, Venezuela), the Delta Amacuro indigenous health office and community leaders. The study was registered in a primary World Health Organization registry (identifier number RPCEC00000158).

PCV13 appeared to be highly immunogenic in children aged 6 weeks to 6 months with geometric mean concentrations (GMCs) as much as $>20$ times higher than generally observed $[5,6]$. Adequate antibody concentrations $\left(\right.$ i.e. $\geqslant 0.35 \mu \mathrm{g} \cdot \mathrm{mL}^{-1}$ ) in $\geqslant 90 \%$ of children aged $7-23$ months were observed for 11 out of 13 serotypes. In children aged 24-59 months, this was observed for only five out of 13 serotypes (table 1). Antibody concentrations were two to three times higher in children aged 7-23 months and three to 10 times higher in children aged $\leqslant 6$ months compared with those aged $24-59$ months. Low antibody concentrations in children aged 24-59 months may be partly explained by previous colonisation with the vaccine serotype. Of the seven serotypes carried by more than one child pre-vaccination, significantly decreased post-vaccination antibody concentrations were observed for serotypes $6 \mathrm{~A}$ and $23 \mathrm{~F}$ compared with noncarriers $\left(0.35 \mu \mathrm{g} \cdot \mathrm{mL}^{-1}\right.$ versus $1.7 \mu \mathrm{g} \cdot \mathrm{mL}^{-1}, \mathrm{p}<0.01$ and $0.38 \mu \mathrm{g} \cdot \mathrm{mL}^{-1}$ versus $1.1 \mu \mathrm{g} \cdot \mathrm{mL}^{-1}, \mathrm{p}=0.017$, respectively). However, serotype-specific hyporesponsiveness was also observed in children aged $<24$ months for serotypes $6 \mathrm{~A}$ and $19 \mathrm{~A}\left(1.5 \mu \mathrm{g} \cdot \mathrm{mL}^{-1}\right.$ versus $5.3 \mu \mathrm{g} \cdot \mathrm{mL}^{-1}, \mathrm{p}=0.01$ and $1.1 \mu \mathrm{g} \cdot \mathrm{mL}^{-1}$ versus $4.0, \mathrm{p}=0.048$, respectively), albeit with higher overall antibody concentrations.

Pneumococcal carriage varied between communities, ranging from 50\% to $88 \%$ in children. In the 424 vaccinated children vaccine-type carriage decreased significantly $(39-29 \%, \mathrm{p}<0.01)$, while no significant decrease of vaccine-type carriage was detected in 459 unvaccinated controls $(14-12 \%, \mathrm{p}=0.60)$. Among vaccinated children, a statistically significant decrease in vaccine-type carriage was observed in those aged $<24$ months (45-28\%, p<0.01), but not in children aged 24-59 months (36-29\%, p=0.078).

The study area, which is heavily affected by high prevalence rates of pneumococcal carriage and disease, was extremely remote and only accessible by traversing the multiple waterways in the river delta by boat. Nevertheless, a large number of subjects were included in this study. Our results demonstrate for the first time that it may be necessary to adapt the currently recommended vaccine schedules for indigenous children living in unique geographical settings. While high antibody concentrations and a significant reduction in vaccine-type carriage 7 weeks post-vaccination were observed in young children, limited carriage reduction and lower antibody concentrations were measured in Warao children aged 24-59 months. In contrast, in nonindigenous children aged $24-72$ months, $\geqslant 90 \%$ generally reaches GMCs $\geqslant 0.35 \mu \mathrm{g} \cdot \mathrm{mL}^{-1}$ for most serotypes and vaccine-type carriage is reduced 1 month after a single PCV dose [7-9]. Lower antibody concentrations in Warao children aged $\geqslant 24$ months might be the consequence of cumulative exposure to immune-modulating helminth infections [10]. In addition, hyporesponsiveness to some colonising serotypes was observed in Warao children of all ages. However, in carriers, GMCs approximated the threshold of $0.35 \mu \mathrm{g} \cdot \mathrm{mL}^{-1}$ for two serotypes only in those aged $24-59$ months. This phenomenon was previously described in infants [11] and in high-risk children with chronic conditions such as asplenia or immunocompromising disease [9]. For children aged $\geqslant 24$ months considered to be at high risk, two-dose regimens are already recommended [3]. Possibly, this recommendation needs to be extended to indigenous children. The importance of adequate antibody concentrations in children $\geqslant 24$ months lies in the establishment of herd immunity [12], since there is a large pneumococcal reservoir in Warao children aged $\geqslant 24$ months [1]. However, it is difficult to define adequate antibody concentrations. Although $0.35 \mu \mathrm{g} \cdot \mathrm{mL}^{-1}$ is widely used for all serotypes, serotype-specific correlates of protection appear to vary [13]. This is particularly important for serotype $6 \mathrm{~B}$, which was the least immunogenic serotype in our study, while it is responsible for almost $10 \%$ of the invasive pneumococcal disease cases in Latin America [14]. It has been suggested that an antibody concentration of $0.16 \mu \mathrm{g} \cdot \mathrm{mL}^{-1}$ is sufficient to protect against disease by serotype $6 \mathrm{~B}$ [13]. However, the proportion of children aged $24-59$ months with concentrations for $6 \mathrm{~B} \geqslant 0.16 \mu \mathrm{g} \cdot \mathrm{mL}^{-1}$ was still low $(67 \%)$. Non-antibody mediated immune responses also seem to play an important role in 
TABLE 1 Pneumocccal serotype-specific antibody geometric mean concentrations (GMCs) and proportion of antibody concentrations $\geqslant 0.35 \mu \mathrm{g} \cdot \mathrm{mL}^{-1}$ following 13-valent pneumococcal conjugate vaccine (PCV13) vaccination of Warao Amerindian children aged 6 weeks to 59 months

\begin{tabular}{|c|c|c|c|c|c|c|c|c|c|c|}
\hline & \multicolumn{3}{|c|}{$\begin{array}{l}\text { Children with one vaccine } \\
\text { dose (24-59 months) }\end{array}$} & \multicolumn{3}{|c|}{$\begin{array}{l}\text { Children with two vaccine } \\
\text { doses (7-23 months) }\end{array}$} & \multicolumn{3}{|c|}{$\begin{array}{l}\text { Children with three vaccine } \\
\text { doses ( } 6 \text { weeks to } 6 \text { months) }\end{array}$} & \multirow{2}{*}{$\begin{array}{c}\text { Differences in antibody } \\
\text { concentration } 6 \text { weeks } \\
\text { to } 23 \text { months versus } \\
24-59 \text { months } \\
\text { p-value }\end{array}$} \\
\hline & $\begin{array}{c}\text { GMC } \\
\text { post-vaccination } \\
(95 \% \mathrm{Cl})\end{array}$ & $\begin{array}{c}\text { Fold rise } \\
\text { post- versus } \\
\text { pre-vaccination }\end{array}$ & $\begin{array}{c}\operatorname{lgG} \\
\geqslant 0.35 \mu \mathrm{g} \cdot \mathrm{mL}^{-1}\end{array}$ & $\begin{array}{c}\text { GMC } \\
\text { post-vaccination } \\
{[95 \% \mathrm{CI})}\end{array}$ & $\begin{array}{c}\text { Fold rise } \\
\text { post- versus } \\
\text { pre-vaccination }\end{array}$ & $\begin{array}{l}\operatorname{lgG} \\
\geqslant 0.35 \mu \mathrm{g} \cdot \mathrm{mL}^{-1}\end{array}$ & $\begin{array}{c}\text { GMC } \\
\text { post-vaccination } \\
(95 \% \mathrm{Cl})\end{array}$ & $\begin{array}{c}\text { Fold rise } \\
\text { post- versus } \\
\text { pre-vaccination }\end{array}$ & $\frac{\operatorname{lgG}}{\geqslant 0.35 \mu \mathrm{g} \cdot \mathrm{mL}^{-1}}$ & \\
\hline $\begin{array}{l}\text { Subjects } \mathbf{n} \\
\text { Serotypes }\end{array}$ & & 287 & & & 109 & & & 25 & & 421 \\
\hline 1 & $1.2(1.1-1.4)$ & 11 & 84 & $4.3(3.4-5.3)$ & 38 & 97 & $21.7(15.9-29.6)$ & 241 & 100 & $<0.01$ \\
\hline 3 & $3.7(3.3-4.1)$ & 13 & 99 & $7.0(5.9-8.4)$ & 28 & 100 & $10.4(7.7-14.0)$ & 54 & 100 & $<0.01$ \\
\hline 4 & $0.67(0.59-0.75)$ & 7 & 74 & $2.2(1.8-2.6)$ & 21 & 95 & $8.1(5.7-11.6)$ & 123 & 100 & $<0.01$ \\
\hline 5 & $1.3(1.1-1.5)$ & 16 & 87 & $4.1(3.3-5.1)$ & 60 & 100 & $25.4(18.6-34.7)$ & 541 & 97 & $<0.01$ \\
\hline $6 \mathrm{~A}$ & $1.6(1.3-2.0)$ & 34 & 80 & $3.8(2.9-5.0)$ & 152 & 91 & $13.6(3.4-24.9)$ & 205 & 96 & $<0.01$ \\
\hline $6 \mathrm{~B}$ & $0.36(0.28-0.46)$ & 9 & 51 & $0.37(0.26-0.52)$ & 19 & 57 & $3.5(1.7-7.2)$ & 51 & 88 & 0.037 \\
\hline $7 \mathrm{~F}$ & $5.7(5.1-6.4)$ & 61 & 100 & $10.6(9.1-12.4)$ & 105 & 100 & $29.7(22.8-38.6)$ & 395 & 100 & $<0.01$ \\
\hline $9 \mathrm{~V}$ & $0.94(0.80-1.1)$ & 10 & 75 & $1.9(1.5-2.4)$ & 29 & 90 & $11.7(8.1-16.9)$ & 180 & 100 & $<0.01$ \\
\hline 14 & $2.0(1.7-2.4)$ & 22 & 86 & $4.3(3.5-5.2)$ & 97 & 99 & $19.2(14.9-24.8)$ & 100 & 100 & $<0.01$ \\
\hline $18 \mathrm{C}$ & $1.8(1.6-2.1)$ & 25 & 91 & $4.4(3.6-5.3)$ & 70 & 100 & $18.2(14.0-23.6)$ & 239 & 100 & $<0.01$ \\
\hline $19 \mathrm{~A}$ & $1.6(1.4-1.9)$ & 8 & 90 & $3.2(2.6-4.0)$ & 16 & 100 & $9.1(6.9-12.0)$ & 63 & 100 & $<0.01$ \\
\hline $19 \mathrm{~F}$ & $4.9(4.3-5.7)$ & 20 & 97 & $9.5(7.5-12.1)$ & 70 & 98 & $31.9(22.5-45.2)$ & 96 & 100 & $<0.01$ \\
\hline $23 \mathrm{~F}$ & $1.0(0.82-1.2)$ & 10 & 70 & $1.1(0.85-1.5)$ & 19 & 79 & $9.2(4.9-17.2)$ & 101 & 96 & $<0.01$ \\
\hline
\end{tabular}


acquisition and duration of pneumococcal carriage. Recently, it was shown that the balance between T-helper 17 and regulatory T-cells is critically associated with the clearance of carriage from the nasopharynx [15]. This balance is also distorted by chronic intestinal helminth infections [10].

The findings of our study have to be interpreted in the light of its limitations. The study had no age-matched comparator arm since it was deemed unethical to deprive vulnerable Warao children of the vaccine after reaching these geographically isolated areas. Additionally, a comparison between communities would be affected by the difference in baseline colonisation rates. Because all samples were taken during the rainy season, it is very unlikely that the observed carriage shifts were season-related. The inclusion of unvaccinated siblings and caregivers clearly showed that vaccine-type carriage only decreased significantly in vaccinated children.

In conclusion, while PCV13 was highly immunogenic in Warao children aged $<24$ months, children aged 24-59 months did not reach adequate antibody concentrations for a majority of serotypes after one catch-up dose. Higher antibody concentrations in younger children were accompanied by a significant decrease in nasopharyngeal carriage of vaccine-type pneumococci. Before PCV guidelines based on studies in healthy non-native children are extrapolated to vulnerable indigenous childhood populations, critical evaluation of the need for possible adjustments in dosing schedules is warranted.

@ERSpublications

PCV13 catch-up regimens for children aged $\geqslant 24$ months may need to include more than one vaccine dose http://ow.ly/lstI3023i2R

Lilly M. Verhagen ${ }^{1,2,3}$, Ismar A. Rivera-Olivero ${ }^{1}$, Meyke Hermsen ${ }^{4}$, María Carolina Sisco ${ }^{1}$, Mailis Maes ${ }^{1}$, Berenice del Nogal $^{5}$, Debby Bogaert ${ }^{3}$, Guy A.M. Berbers ${ }^{6}$, Peter W.M. Hermans ${ }^{2}$, Marien I. de Jonge ${ }^{2}$ and Jacobus H. de Waard ${ }^{1}$

${ }^{1}$ Laboratorio de Tuberculosis, Instituto de Biomedicina, Universidad Central de Venezuela, Caracas, Venezuela. ${ }^{2}$ Laboratory of Paediatric Infectious Diseases, Dept of Paediatrics, Radboud Institute for Molecular Life Sciences, Radboud University Medical Centre, Nijmegen, The Netherlands. ${ }^{3}$ Dept of Paediatric Immunology and Infectious Diseases, Wilhelmina Children's Hospital Utrecht, Utrecht, The Netherlands. ${ }^{4}$ Dept of Pathology, Radboud University Medical Centre, Nijmegen, The Netherlands. ${ }^{5}$ Dept of Paediatrics, Children's Hospital J.M. de los Ríos, Universidad Central de Venezuela, Caracas, Venezuela. ${ }^{6}$ Centre for Infectious Disease Control, National Institute of Public Health and the Environment, Bilthoven, The Netherlands.

Correspondence: Lilly M. Verhagen, Wilhelmina Children's Hospital Utrecht, Dept of Paediatric Immunology and Infectious Diseases, Lundlaan 63584 EA Utrecht, The Netherlands. E-mail: L.M.Verhagen-4@umcutrecht.nl

Received: May 042016 | Accepted after revision: June 302016 | First published online: Aug 182016

Clinical trial: This study is registered at http://rpcec.sld.cu/ with identifier number RPCEC00000158.

Support statement: This work was supported by Pfizer Venezuela. Additionally, the study was funded by the Fundacion para la Investigación en Micobacterias (FUNDAIM), Caracas, Venezuela. The work was partly supported by "Integrated Microsystems for Biosensing (3E-01), FES0901:FES HTSM", a project of NanoNextNL, a micro- and nanotechnology consortium of the government of the Netherlands and 130 partners. The funders had no role in study design, data collection and analysis, decision to publish, or preparation of the manuscript. Funding information for this article has been deposited with the Open Funder Registry.

Conflict of interest: Disclosures can be found alongside this article at erj.ersjournals.com

Acknowledgements: The authors thank the participating families and the field workers involved in the recruitment and sampling of children, in particular the medical students of the Escuela de Medicina José Maria Vargas of the Universidad Central de Venezuela and Thor Küchler, Marcella Overeem and Stèphan Kraai (Laboratorio de Tuberculosis, Instituto de Biomedicina, Universidad Central de Venezuela, Caracas, Venezuela and Laboratory of Paediatric Infectious Diseases, Dept of Paediatrics, Radboud Institute for Molecular Life Sciences, Radboud University Medical Centre, Nijmegen, the Netherlands). Furthermore, we thank Jochem Burghouts (Laboratorio de Tuberculosis, Instituto de Biomedicina, Universidad Central de Venezuela and Laboratory of Paediatric Infectious Diseases, Dept of Paediatrics, Radboud Institute for Molecular Life Sciences) for facilitation of study logistics. At the RIVM (National Institute for Health and Environment, Bilthoven, the Netherlands), we thank Irina Tcherniaeva for technical support. We are grateful to the personnel of the Laboratorio de Tuberculosis, Instituto de Biomedicina (Universidad Central de Venezuela, Caracas, Venezuela), and we acknowledge Rogier Donders (Dept of Health Evidence, Radboud University Medical Centre) for statistics support.

\section{References}

1 Rivera-Olivero IA, Bogaert D, Bello T, et al. Pneumococcal carriage among indigenous Warao children in Venezuela: serotypes, susceptibility patterns, and molecular epidemiology. Clin Infect Dis 2007; 45: 1427-1434.

2 Villalba JA, Liu Y, Alvarez MK, et al. Low child survival index in a multi-dimensionally poor Amerindian population in Venezuela. PloS One 2013; 8: e85638.

3 Centers for Disease Control and Prevention Advisory Committee on Immunization Practices (ACIP). Licensure of a 13 -valent pneumococcal conjugate vaccine (PCV13) and recommendations for use among children. MMWR Morb Mortal Wkly Rep 2010; 59: 258-261. 
4 Donders AR, van der Heijden GJ, Stijnen T, et al. Review: a gentle introduction to imputation of missing values. J Clin Epidemiol 2006; 59: 1087-1091.

5 Payton T, Girgenti D, Frenck RW, et al. Immunogenicity, safety and tolerability of 3 lots of 13-valent pneumococcal conjugate vaccine given with routine pediatric vaccinations in the United States. Pediatr Infect Dis J 2013; 32: 871-880.

6 Gutiérrez Brito M, Thompson A, Girgenti D, et al. Immunogenicity and safety of 13-valent pneumococcal conjugate vaccine in Mexico. Rev Panam Salud Publica 2013; 33: 414-421.

7 Wysocki J, Brzostek J, Szymański H, et al. Immunogenicity and safety of a 13-valent pneumococcal conjugate vaccine administered to older infants and children naïve to pneumococcal vaccination. Vaccine 2015; 33: 1719-1725

8 Vesikari T, Karvonen A, Korhonen T, et al. Immunogenicity of 10-valent pneumococcal nontypeable Haemophilus influenzae protein $\mathrm{D}$ conjugate vaccine when administered as catch-up vaccination to children 7 months to 5 years of age. Pediatr Infect Dis J 2011; 30: e130-e141.

9 Rivera-Olivero IA, Del Nogal B, Fuentes M, et al. Immunogenicity of a 7-valent pneumococcal conjugate vaccine (PCV7) and impact on carriage in Venezuelan children at risk of invasive pneumococcal diseases. Vaccine 2014; 32: 4006-4011.

10 Figueiredo CA, Barreto ML, Rodrigues LC, et al. Chronic intestinal helminth infections are associated with immune hyporesponsiveness and induction of a regulatory network. Infect Immun 2010; 78: 3160-3167.

11 Madhi SA, Violari A, Klugman KP, et al. Inferior quantitative and qualitative immune responses to pneumococcal conjugate vaccine in infants with nasopharyngeal colonization by Streptococcus pneumoniae during the primary series of immunization. Vaccine 2011; 29: 6994-7001.

12 Strutton DR, Farkouh RA, Rubin JL, et al. Modeling the impact of the 13-valent pneumococcal conjugate vaccine serotype catch-up program using United States claims data. BMC Infect Dis 2012; 12: 175.

13 Andrews NJ, Waight PA, Burbidge P, et al. Serotype-specific effectiveness and correlates of protection for the 13-valent pneumococcal conjugate vaccine: a postlicensure indirect cohort study. Lancet Infect Dis 2014; 14: $839-846$.

14 Castañeda E, Agudelo CI, Regueira M, et al. Laboratory-based surveillance of Streptococcus pneumoniae invasive disease in children in 10 Latin American countries: a SIREVA II project, 2000-2005. Pediatr Infect Dis J 2009; 28: e265-e270.

15 Mubarak A, Ahmed MS, Upile N, et al. A dynamic relationship between mucosal T helper type 17 and regulatory T-cell populations in nasopharynx evolves with age and associates with the clearance of pneumococcal carriage in humans. Clin Microbiol Infect 2016; in press [DOI: 10.1016/j.cmi.2016.05.017].

\section{Multidrug-resistant tuberculosis in children in northwest Russia: an observational cohort study}

\section{To the Editor:}

Russia has the third highest absolute number of multidrug-resistant (MDR) tuberculosis (TB) cases in the world [1], yet little is known about the scale of childhood MDR-TB in the country; available publications are limited to small case series in older children $[2,3]$. Successful treatment outcomes for children with MDR-TB vary widely in other settings, ranging from 53\% to $97 \%$ [4].

The Arkhangelsk region has one of the highest rates of MDR-TB in Russia [5]. The first paediatric MDR-TB case was registered in 2001. The Arkhangelsk Regional Tuberculosis Dispensary, a state healthcare tertiary TB centre, coordinates care for all patients with drug-resistant TB in the region and works closely with two paediatric sanatoriums.

We conducted a retrospective cohort study of all children ( $<18$ years) diagnosed with MDR-TB in the region, from January 1, 2001 to December 31, 2012 with follow-up data to December 31, 2015. Data were extracted from patient health records and treatment cards. In the Russian national TB programme, childhood TB is disaggregated into younger children ( $<15$ years) and adolescents ( $15-18$ years). This cut-off was preserved to align with country reporting.

MDR-TB was considered as confirmed or clinically-diagnosed. Confirmed cases were verified by culture and drug-sensitivity testing and/or molecular testing. Clinically diagnosed cases were defined according to published consensus definitions [6] and TB severity was categorised based on established criteria [7]. Children with sputum smear- or culture-positive MDR-TB were treated as in-patients at the dispensary until they were considered non-infectious; most sputum culture-negative cases were treated in the paediatric sanatoriums. A few children were managed at home with directly observed therapy (DOT). 